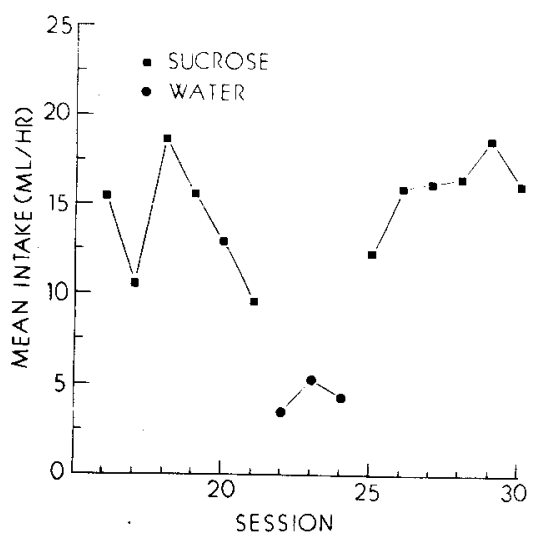

Fig. 2. Mean sucrose and water intake over last 15 experimental sessions expressed in milliliters.

Results and Discussion

Figure 3 shows mean intake of sucrose and water over the entire experimental period. One $S$ in the deprived condition died before shift data could be collected. Sign tests were performed as in Experiment 1. None were significant beyond a criterion of $\mathrm{p}<.05$ : deprived group, $\mathrm{N}=7, \mathrm{p}<.062$; nondeprived group, $\mathrm{N}=7, \mathrm{p}<.227$.

These data indicate that sex differences cannot account for the absence of contrast effects using sucrose as the incentive. CONCLUSIONS

The absence of evidence for positive contrast of intake of sucrose under the conditions of these three experiments seriously questions the simple role of palatability shifts in contributing to the results reported earlier with saccharin (Ashton, Gandelman, \& Trowill, 1970; Gandelman \& Trowell, 1969). However, the procedures should be replicated using other concentrations of sucrose before a definite sucrose-saccharin intake difference can be proposed. Such a replication is currently being carried out in our laboratory.

A second consideration involves the response measure to be used in assessing responding following palatability shifts. Other data collected in our laboratory shows that positive contrast is obtained using sucrose when the short-term postshift lick rate is examined (Ashton \& Trowill, 1970; Panksepp \& Trowill, in press). However, in each instance with licking, the postshift elation is short-lived, and lick rate rapidly assumes a level appropriate for the solution available. Apparently, such a transient increase would be completely obscured when intake is measured over a long term such as was done here.

In any event, a sweet taste ( $8 \%$ sucrose) is not necessarily a sweet taste $(.25 \%$

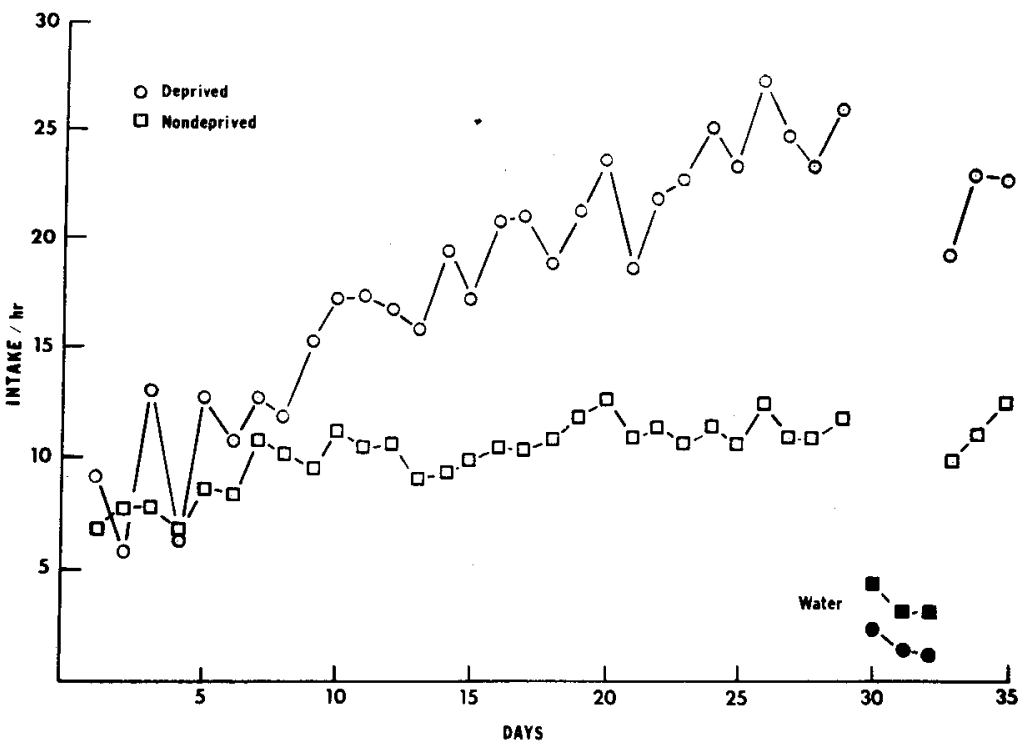

Fig. 3. Mean sucrose and water intake over the entire experimental period expressed in milliliters.

saccharin) to a rat when his responding is measured under conditions like those employed in this set of studies.

ASHTON, A., \& TROWILL, J. A. Effects of reinforcement shifts upon lick rate. Psychonomic Science, $1970,21,8-10$.

GANDELMAN, R., \& TROWILL, J. A. Lffects of reinforcement shifts upon subsequent saccharin consumption. Psychonomic Science, $1969,15,25$.

REFERENCES

ASHTON, A., GANDELMAN, R., \& TROWILL, J. Effect of food deprivation upon elation of saccharin drinking following a temporary shift to water. Psychonomic Science, 1970a, 21, $5-6$.

ILL, J. A. Positive and negative contrast in licking with shifts in sucrose concentration as a function of food deprivation. Learning \& Motivation, in press.

\title{
Effects of reinforcement shifts upon lick rate*
}

\author{
ALAN B. ASHTON $\dagger$ and JAY A. TROWILL \\ University of Massachusetts, Amherst, Mass. 01002
}

Marked increments in lick rate were observed in saccharin drinking following a temporary shift to water in both deprived and nondeprived rats. Similar increases were not observed when sucrose was the reward. Similarities and differences of lick rate data to intake data were discussed.

Immediate and durable positive contrast effects have been observed in saccharin drinking following a temporary shift to tap

*This study was partially supported by USPHS Grant MH-13155-02.

+ Reprints may be obtained by writing the first author. Present address: Department of Psychology, Saginaw Valley College, $225 n$ Pierce Road, University Center, Michigan 48710. water (Ashton, Gandelman, \& Trowill, 1970a; Gandelman \& Trowill, 1969). This same effect, however, was not observed in sucrose drinking (Ashton, Gandelman, \& Trowill, 1970b). The present experiments examine more closely the actual consummatory response during these palatability shifts, using lick rate as the dependent measure. 


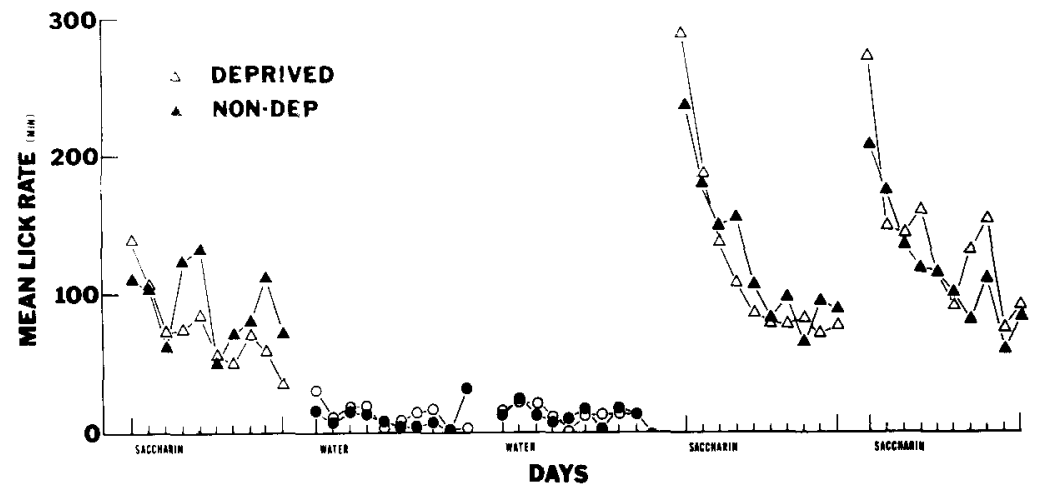

Fig. 1. Mean minute-by-minute lick rates for saccharin and water over the last 5 days of testing.

\section{EXPERIMENT 1}

Subjects

Ten 60-day-old female albino rats, bred in the University of Massachusetts Psychology Department colony, were selected from a group prescreened as saccharin drinkers. Five Ss were maintained on an ad lib feeding schedule (Purina Lab Chow) while the remaining five received $7 \mathrm{~g}$ of food daily $1 \frac{1 / 2}{\mathrm{~h}}$ after testing. All Ss were individually housed in a ventilated room under conditions of continuous illumination. All were allowed continuous access to water.

\section{Apparatus}

For testing each $S$ was placed in a test chamber measuring $30 \mathrm{~cm}$ long $x$ $24 \mathrm{~cm}$ wide $\times 45 \mathrm{~cm}$ high. A drinking tube was positioned on the outside such that the nipple was accessable through a $2 \times 1 \mathrm{~cm}$ oval hole in a Plexiglas shield. The nipple was recessed approximately $5 \mathrm{~mm}$ to prevent Ss from holding the drinking spout. Discrete tongue contacts were recorded using an electronic drinkometer and digital counters.

Procedure

Each $S$ was allowed 10 days of experience with the experimental chamber and the $.25 \%(w / w)$ sodium saccharin-tap water solution ( $\mathrm{sacc}$ ). During these 10-min exposures the lick rate stabilized and Ss began to respond immediately when placed in the box. The test sessions also lasted $10 \mathrm{~min}$ with licks recorded by minute blocks for purposes of analysis. Testing consisted of 1 day of sacc followed by 2 days of tap water and finally by 2 days of sacc.

\section{Results and Discussion}

Figure 1 shows mean minute-by-minute lick rates for the 5 test days. Postshift responding under both deprivation conditions is clearly higher than preshift levels, particularly in the first minutes, where response rates are more than doubled (pre-post main effect, $F=12.60$, $\mathrm{df}=1 / 8, \quad \mathrm{p}<.01 ;$ Pre-post by Minute interaction, $\mathrm{F}=4.12, \mathrm{df}=9 / 72, \mathrm{p}<.001)$. All individual response rates $(\mathrm{N}=10)$ showed marked increases during the first 2 min of testing after the water shift.

These data are somewhat contradictory to those of Ashton, Gandelman, \& Trowill (1970a), which showed that the elated postshift responding was suppressed under comparable deprivation levels when intake was the dependent measure. The data do not offer a ready resolution of this conflict, but it seems likely that the differences may simply be accounted for by differences in session length. Nondeprived Ss in the earlier study may have continued to drink throughout the 1-h session where the deprived animals stopped before the end of the session, perhaps due to a lesser fluid need (Bolles, 1967, pp. 203-206).

\section{EXPERIMENT 2}

\section{Subjects}

Ten 60-day-old female albino rats were selected and maintained in two groups as in Experiment 1. These animals were prescreened as sucrose drinkers.

Apparatus and Procedure

Apparatus and procedure were identical to those described in Experiment 1 except

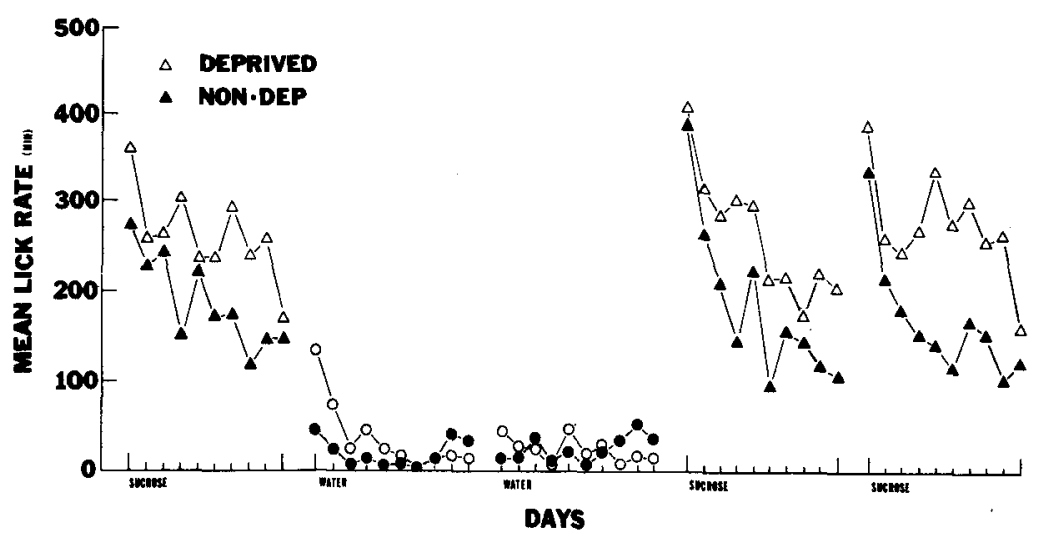

Fig. 2. Mean minute-by-minute lick rates for sucrose and water over the last 5 days of testing. that a $16 \%(\mathrm{w} / \mathrm{w})$ sucrose-tap water solution replaced the saccharin solution.

Results and Discussion

Figure 2 shows mean minute-by-minute lick rates for the 5 test days. The overall group main effect was significant $(F=11.58, \mathrm{df}=1 / 8, \mathrm{p}<.01)$, indicating that the deprived animals responded at a higher rate than did the nondeprived animals. No other terms of the analysis of variance were significant, although mean lick rates during the first minutes of postwater sucrose drinking were generally higher for both groups (Pre-post by Minute interaction, $\mathrm{F}=1.88$, $\mathrm{df}=9 / 72, \mathrm{p}<.10$ ). The relative increase was greater for the nondeprived condition. An examination of individual protocols revealed that all animals $(\mathrm{N}=5)$ in the nondeprived group showed significant increases in lick rate during the first minute of postwater drinking compared to an equal time of prewater drinking, whereas the deprived group did not show a unanimous directional shift. (Three animals increased their rates, while two showed a decrease.)

Although solution concentrations differ, these data are consistent with other findings (Ashton, Gandelman, \& Trowill, $1970 \mathrm{~b}$ ) in that elation of responding was not observed using sucrose with intake as the dependent measure.

\section{DISCUSSION}

The data presented here are, for the most part, consistent with those data reported earlier using intake as the dependent measure (Ashton, Gandelman, \& Trowill, 1970a; Gandelman \& Trowill, 1969) with the exception that deprived animals licking for saccharin did show an elation effect following a brief shift to water. However, since lick rate tends to be invarient over may conditions (Bolles, 1967, pp. 202-203), palatability shifts would not be expected to grossly affect the lick rate itself, but rather the persistence of drinking. Although lick rate may show an 
elation or positive contrast effect in the first minutes of testing, the rate rapidly returns to nominal preshift levels. This may account for the discrepancy between the results reported here and those using in take data (Ashton, Gandelman, \& Trowill, 1970a).

Of further interest is the differential effect of response ceiling between Experiments 1 and 2. Assuming that rats lick at a rate of 6 per second (Stellar \& Hill, 1952), the per minute rate could be as high as 360 licks. Preshift rates in Experiment 1 were well below this rate, and both groups showed marked contrast effects. In Experiment 2, however, preshift rates were higher and, even though the absolute level of postshift responding was considerably greater than in Experiment 1 , the relative contrast effect was smaller. Different baselines and response ceiling effects also affected the two groups within Experiment 2 such that the increases in response rate were greater for the nondeprived animals (although these only approached statistical significance). These data compliment those of Panksepp \& Trowill (1969, 1970, in press), which indicated that manipulations that alter baseline responding (e.g., deprivation conditions) also affect contrast effects. It might also be suggested that the ability to obtain elation effects could depend strongly on the solution concentrations selected.

\section{REFERENCES}

ASHTON, A., GANDELMAN, R., \& TROWILL, J. A. Effect of food deprivation upon elation of saccharin drinking following a temporary shift to water. Psychonomic Science, 1970a $21,5-6$

ASHTON, A., GANDELMAN, R., \& TROWILL, J. A. Effects of reinforcement shifts upon subsequent sucrose consumption. Psychonomic Science, 1970b, 21, 8-10.

BOLLES, R. C. Theory of motivation. New York: Harper \& Row, 1967.

GANDELMAN, R., \& TROWILL, J. A. Effects of reinforcement shifts upon subsequent saccharin consumption. Psychonomic Science, $1969,15,25$.

PANKSEPP, J., \& TROWILL, J. A. Positive and negative contrast effects with hypothalamic reward. Physiology \& Behavior, 1969, 4, 173-175.

PANKSEPP, J., \& TROWILL, J. A. Positive incentive contrast with rewarding electrical stimulation of the brain. Journal of Comparative \& Physiological Psychology, 1970, 70, 358-364.

PANKSEPP, J., \& TROWILL, J. A. Positive and negative contrast in licking with shifts in sucrose concentration as a function of food deprivation. Learning \& Motivation, in press. STELLAR, E., \& HILL, J. H. The rat's rate of drinking as a function of water deprivation. Journal of Comparative \& Physiological Psychology, 1952, 45, 96-102.

\section{Responses to palatability shifts: Effects of varying the retention level}

\author{
RODNEY DUBE, ALAN B. ASHTON,** and JAY A. TROWILL $†$ \\ University of Massachusetts, Amherst, Mass. 01002
}

Nondeprived rats were given a 1-h exposure to a sodium-saccharin solution for 28 consecutive days. A temporary shift to tap water then occurred for all Ss. The brief timeout (tap water) led to a positive contrast effect. Lengthy exposure to tap water (30 days) resulted in the possible forgetting of the comparison solution (sacc) or perhaps the response to that solution.

Recent studies (Gandelman \& Trowill, 1969; Ashton, Gandelman, \& Trowill, 1970a) have noted an immediate and durable elation effect when nondeprived rats are returned to a sodium-saccharin solution after being given a timeout from this solution. Typically, the procedure involved the presentation of a

\footnotetext{
*Present address: Psychology Department, Saginaw Valley College, University Center, Michigan, 48710.

† Reprints may be obtained by writing the third author.
}

period would interfere with the retention of the ingestion response (sacc). Gleitman \& Steinman (1964), using a runway paradigm, demonstrated that rats forget previously experienced reward magnitudes and perhaps their own responses to reward-magnitude shifts after interposition of a 2-month retention interval. The present experiment investigated the effect of varying the retention interval during which the rat sampled only tap water.

\section{SUBJECTS}

Twenty-four 90-day-old female albino rats, bred at the University of Massachusetts colony, were selected from a larger group prescreened as saccharin drinkers. All Ss were individually housed and maintained on ad lib food (Purina Lab Chow pellets) and tap water in a ventilated room under conditions of illumination from 7 a.m. to 7 p.m. All testing was done in the S's home cage from 11 a.m. to 12 noon.

\section{PROCEDURE}

The $24 \mathrm{Ss}$ were assigned randomly to four groups (6 Ss/group). A graduated water bottle (Wahmann LC.274) c ontaining $0.25 \% \quad(w / w)$ sodium-saccharin/tap-water solution (sacc) was attached to each cage for $1 \mathrm{~h}$ during 28 consecutive days. On the 29th day, tap water was substituted for the more palatable saccharin. Group 1 experienced tap water for $10 \mathrm{~min}$ and Group 2 experienced tap water for $1 \mathrm{~h}$. Saccharin was returned to these two groups on the day following tap water for 7 days. Group 3 consumed tap water for $1 \mathrm{~h}$ on 3 consecutive days and was then returned to saccharin for 7 days. Group 4 ingested tap water for $1 \mathrm{~h}$ for 30 consecutive days and was then returned to saccharin for 7 days.

\section{RESULTS AND DISCUSSION}

Figure 1 shows the mean intake of saccharin and tap water over the entire experimental period. Visual inspection of the data for the first 28 days lead to the conclusion that there was no significant difference between groups. In a comparison between the 3 days preceding and the 3 days after the shift to tap water, Group 1 showed an elated postshift intake $(\mathrm{F}=15.11 ; \mathrm{df}=1,20 ; \mathrm{p}<.001)$. All six Ss of this group increased ingestion of saccharin during the postshift period (significant by a sign test according to Siegel, 1956, p. 68). Group 2 also demonstrated an elated intake effect $(\mathrm{F}=12.45 ; \mathrm{df}=1,20 ; \mathrm{p}<.005)$ but failed to meet significance for a sign test. A single $S$ in this group consumed a mean of $2 \mathrm{ml}$ less during the postshift period.

Group 3, which had 3 days of $1 \mathrm{~h}$ tap water, failed to meet significance on either the $F(F=0.92 ; d f=1,20 ; p>.10)$ or the sign test. This finding is inconsistent with 